Author's accepted manuscript

The published version of this paper is available online at:

http://dx.doi.org/ 10.12968/pnur.2017.28.4.168

Please cite this paper as:

Duncan D, Hayes S (2017). The development of the GP nurse role: drivers and change agents, Practice Nursing 28(4), 168-171 


\section{The development of the GP nurse role: drivers and change agents}

\section{Debbie Duncan and Sian Hayes}

After the publication of Health Education England's General Practice Workforce Development Plan, Debbie Duncan and Sian Hayes review the history of change in general practice nursing and examine the direction in which the new document may point the profession.

In recent weeks we have seen the publication of Health Education England's General Practice Workforce Development Plan (HEE, 2017). Its aim is to improve training available in general practice settings - raising the profile of general practice nurses (GPNs) is key to helping to retain and expand a position within the nursing profession which has previously been called a Cinderella role (HEE, 2017; While and Webley-Brown, 2017). So why is the General Practice Workforce Development Plan such an important document? To understand the implication of it we need to look at the history of the GPN.

The role of GPNs has changed rapidly through the past few decades. They hold a key position within primary care, often reducing the stretch on general practitioners (Baird et al, 2016). Initially nurses were attracted to the role because of the regular hours and non-shift work (Queen's Nursing Institute (QNI), 2017a), as well as the holistic approach of working with individuals and families and the variety of extended roles and responsibilities.

Historically the GPN role was to contribute to the delivery of the GP contract across the spectrum of healthcare provision and the life course of the practice population. The role of the GPN saw significant financial support and development in the 1960s. The first contract between General Practitioners (GPs) and the National Health Service (NHS) was finalised to include funding for ancillary staff which included nurses in 1966 (QNI, 2017). Their initial role involved working as treatment-room nurses (Cartwright and Scott, 1961). This expanded to see them working within GP surgeries to assess, screen and treat patients of all ages and nationalities. They also offered health-promotion advice in areas such as contraception, weight loss, smoking cessation and travel health.

There was no significant change until the 1990s and the introduction of the 'internal market' in which, for the first time, GPs were given budgets to commission services for their local populations. This was a big stimulus for change as the new contract included chronic disease clinics and incentives to meet the population target rates for vaccinations and cervical screening. GPs responded by employing nurses to provide these services (McGee and Castledine, 1999).

Also during the 1990s, the Royal College of Nursing (RCN) practice nurse forum lobbied for specialist practitioner recognition from the United Kingdom Central Council. This was achieved in 1994 (UKCC, 1994) although there was still not a recognised qualification.

Changes to the GP contract in 1989 (which were implemented in 1990) had a huge impact on the role of the GPN. They changed the emphasis from general practice being curative and reactive to being preventive and proactive. The management of long-term conditions and health promotion was by and large delegated to GPNs and as a result the numbers of nurses employed increased as did the need for further specialised education. In fact, research showed that although nurses needed longer consultations for these patients, they did provide effective care (Laurant et al, 2005; Woodroffe E, 2006). A later Cochran review showed that there were no consistent differences in problem recognition, examination, prescribing, referral or diagnostic test rates, or in patient satisfaction between GP and GPN consultations, (Wilson et al, 2006). This extended role became an important consideration when employing new staff. GPNs were also shown to offer effective services for patients with minor illnesses/ailments and those requiring same day appointments (Shum et al, 
2000).

In 2004 the General Medical Services (GMS) contract was renewed and introduced the Quality and Outcomes Framework (QOF), a voluntary scheme aimed at giving GPs an incentive to provide other amenities in addition to their core services. For the first time, GPs began to employ healthcare support workers or healthcare assistants (HCA) in order to release the capacity of GPNs to focus on this specialised work. HCAs were shown to make an increasingly useful contribution to the skill mix in general practice (Bosley and Dale, 2008). The incentive to educate and encourage the development of the GPN role in general practice continued (Sibbald \& Laurant, 2006).

Alongside the changes in the contractual arrangements with general practice, we also had the 2000 NHS Plan which stated that 'the future of the NHS Plan rests on the strength of its primary care services', which required the introduction of new models of general practice (Department of Health (DoH), 2000). In addition, 2002 saw the Chief Nursing Officer introducing the Liberating the Talents paper which set out 10 key steps for nurses in extending and advancing their clinical roles (DoH, 2002).

Within a decade we saw a shift from Labour to Conservative government, and the landscape of primary care changed again as new commissioning groups, Health Education England (HEE) and the Local Education and Training Boards (LETBs) were born (DoH, 2012a; DoH, 2012b). The aim of the changing face of new primary care was to see the more than 80,000 people with complex needs receiving bespoke GP-led proactive and personalised care by 2014 (DoH, 2012b). The idea was to also see improvements in communication between GP practices and other services, including community nursing services, A\&E, ambulance services, care homes, and mental health and social care teams (DoH, 2012b). Again the workload of the nursing team increased in response to these demands, including the requirement for GPNs to support the educational requirements of healthcare assistants.

In 2015 the framework for a Care Certificate was published by HEE to replace the National Minimum Training Standards (NMTS) and the Common Induction Standards (CIS) that had historically provided the framework for those working within health and social care respectively (HEE, 2015b).

The 2016 Five Year Forward plan (NHS England, 2016) makes a variety of suggestions to support general practice. One is that Clinical Care Groups (CCGs), local authorities and NHS England will be able to pool budgets to jointly commission expanded services which will include the hiring of additional nurses in GP settings to fill a coordination role for patients with long term conditions (The Kings Fund, 2015). To meet some of these new roles they also suggest a GPN development strategy to include improving training capacity in general practice, increasing the number of pre-registration nurse placements, and implementing improvements in retention of the existing nursing workforce and supporting practice nurses to return to work (NHS England, 2016). Such a radical plan will require the investment of an additional $£ 15$ million and a review of the previous piecemeal GPN training (NHS England, 2016).

This plan recognises the potential problems that will occur within in the next five years. It mirrors the QNI report of 2015 which suggested that 33.4\% of the GPN workforce are due to retire by 2020 (Bradby \& McCallum, 2015). The HSCIC Workforce and Development Census in 2013 showed that there were 23,833 GPNs, an increase of 375 (1.6\%) since 2012. There were 14,943 full-time equivalent (FTE) nurses, an increase of 248 (1.7\%) since 2012. Although on the surface GP practices are still recruiting GPNs, this does not reflect the need and there are concerns about the fact that they are still not recruiting many men to this career pathway. The issues with recruiting may be due in part to problems with the employment structure where - unlike that of other community nurses - there can be a wide variety in pay, from $£ 14.60$ to $£ 22.00$ per hour (Bradby and McCallum, 2015). These issues are long standing and need addressing so we can maximise retention and reduce attrition (While and Webley-Brown, 2017).

The QNI report also showed that many practice nurses find it difficult to access ongoing education and 
training (Bradby and McCallum, 2015): 47\% stated that their employers do not necessarily support additional training or even have regular appraisals. It's a real concern if we are also aware that many have had a piecemeal journey through education to get where they are now. In response to some of these issues Health Education England (HEE, 2015a) also launched a district nurse and general practice nursing framework developed in partnership with nursing stakeholders to standardise roles and provide a pathway to plan and develop careers. Previous schemes were mapped against the NHS Knowledge and Skills Framework with no specific nationalised descriptions of practice nursing roles (RCGP, 2012). This framework sets out the core and specific competencies and skills needed for the change from acute to primary and community care. The main aim of this is to provide a much-needed career structure for GPNs, HCAs and Advanced Nurse Practitioners similar to the Royal College of General Practitioners (RCGP) GPN Nursing Service (Fitzmaurice et al, 2015).

Recently HEE (2017) has published the General Practice Workforce Development Plan into what they would say is a landscape a wash with strategic plans and frameworks. The document was produced in response to the Five Year Forward Plan and its requirement for a minimum investment of $£ 15$ million (Bradby and McCallum, 2015; The Kings Fund, 2015). The document aims to offer clear guidance on how to increase recruitment, retention and return to practice (HEE, 2017). It gives clear examples of coherent workforce solutions for sustainable and transformational planning. Its key messages are about entry into the profession, establishing the GPN role, enhancing it and expanding the HCA role (HEE, 2017).

There are five sections within the document that aim to meet these aims with 17 recommendations. Section one is about entry into general practice nursing for pre-registration nursing students. Recommendations include raising the profile of the GPN career, to increase the number of preregistration nursing placements and use of the HEE quality framework. The second section outlines recommendations for the newly qualified GPN. These include strategies to increase employment of nurses on completion of their pre-registration training, preceptor programmes and GPN educator roles. The third section is about enhancing the GPN role and maximising the professional development of the workforce. The recommendations include access to accredited training, having GPN leaders in all CCGs and supporting nurses return to practice. Expanding the workforce support is section four. It recommends that all HCAs hold the Care Certificate, that the number of HCAs in general practice be increased and that their training is aligned to the RCGP framework (RCGP, 2012). The final section recommends a sustainable and accessible tool kit to support GPs to implement these recommendations.

The General Practice Workforce Plan is peppered with examples of innovative practice and ideas for the delivery of educational programmes. Alongside this groundbreaking report from Health Education England, the QNI are currently involved in a consultation process reviewing the education and practice standards for experienced GPNs (QNI, 2017b). Like all competency frameworks, these standards will seek to guide the GPN, their employers and higher education institutions in the expectations of the role of the GPN. As GPNs we have seen huge changes in our role and educational requirements since the 1960s. Our hope is that these reports will shape and help our profession as we move forward into the next decade.

Baird B, Charles A, Honeyman M et al. (2016). Understanding pressures in general practice. King's Fund, London

Bosley S, Dale J (2008). Healthcare assistants in general practice: practical and conceptual issues of skill-mix change. Br J Gen Pract 58(547): 118-124

Bradby M, McCallum C (2015). General practice nursing in the 21st century: a time of opportunity. Queen's Nursing Institute, London 
Cartwright A, Scott R (1961). The work of a nurse employed in a general practice. Br Med J 1(5228): 807-13

Department of Health (2000). The NHS Plan. HMSO, London Department of Health (2002). Liberating the talents. http://webarchive.nationalarchives.gov.uk/20130107105354/http:/ www.dh.gov.uk/prod_consum_dh/groups/dh_digitalassets/@ dh/@en/documents/digitalasset/dh_4076250.pdf

Department of Health (2012a). Liberating the NHS: Developing the Healthcare Workforce. https://www.gov.uk/government/ uploads/system/uploads/attachment_data/file/216421/ dh_132087.pdf

Department of Health (2012b). Transforming primary care. https://www.gov.uk/government/uploads/system/uploads/ attachment_data/file/304139/Transforming_primary_care.pdf

Fitzmaurice D, Moger A, Storey, K (2015). General practice nursing: revisited and reinvigorated. Br J Gen Pract 65(639): e636-e637

Health Education England (2015a). Transforming nursing for community and primary care. https://www.hee.nhs.uk/our- work/developing-our-workforce/nursing/transforming-nursingcommunity-primary-care

Health Education England (2015b). The care certificate. http:// www.skillsforcare.org.uk/Documentlibrary/Standards/Care- Certificate/Care-Certificate-Guidance-final---Feb-2015.pdf

Health Education England (2017) The general practice workforce development plan. https://www.hee.nhs.uk/sites/default/files/ documents/3018\%20HEE\%20GPN\%20plan\%20WEB.pdf

Laurant M, Reeves D, Hermens R et al (2005). Substitution of doctors by nurses in primary. Cochrane Database Syst Rev (2)

McGee P, Castledine G (1999). A survey of specialised and advanced nursing practice in the UK. Br J Nurs 8(16): 1074-78

NHS England (2014). Five years forward view. NHS England, London

NHS England (2016). General practice forward view. https:// www.england.nhs.uk/wpcontent/uploads/2016/04/gpfv.pdf

Queen’s Nursing Institute (2015). District nursing and general practice nursing service: education and career framework. https://www.hee.nhs.uk/sites/default/files/documents/ Interactive\%20version\%20of\%20the\%20framework_1.pdf

Queen's Nursing Institute (2017a).Transition to general practice nursing. https://www.qni.org.uk/wpcontent/uploads/2017/01/ Transition-to-General-Practice-Nursing-CHAPTER-1.pdf

Queen’s Nursing Institute (2017b). General practice nurse standards. https://www.qni.org.uk/exploreqni/policy-practice/ general-practice-nurse-standards/

Royal College of General Practitioners (2012). General Practice Nurse competencies. file://C:/Users/ddunca01/Downloads/ RCGP-GPF-Nurse-Competencies\%20(1).pdf

Shum C, Humphreys A, Wheeler D, Cochrane MA, Clement S (2000). Nurse management of patients with minor illnesses in general practice: multicentre, randomised controlled trial. BMJ 320(7241): 1038-43

Sibbald B, Laurant MG, Reeves D (2006). Advanced nurse roles in UK primary care. Med J Aust 185(1): $10-12$

The King's Fund (2015). The NHS five year forward http://www. kingsfund.org.uk/projects/nhs-fiveyear-forward-view?gclid=CL Kx6eqv7sYCFYvHtAodIhcLSA (accessed 12 March 2017)

UKCC (1994) The Standards for Post registration Education and Practice Project. London: UKCC 
While A, Webley-Brown C (2017). General practice nursing: who is cherishing this workforce? London J Prim Care 9(1): 10-13

Wilson AD, Childs S (2006). Effects of interventions aimed at changing the length of primary care physicians’ consultation. Cochrane Database Syst Rev (1)

Woodroffe E (2006). Nurse-led general practice: the changing face of general practice? $\mathrm{Br} J \mathrm{Gen}$ Pract 56(529): 632-3 